\title{
Predictors of Serostatus Disclosure to Partners Among Young People Living with HIV in the Pre- and Post-HAART Eras
}

\author{
Philip Batterham, ${ }^{1}$ Eric Rice, ${ }^{1}$ and Mary Jane Rotheram-Borus ${ }^{1,2}$
}

\begin{abstract}
Received Apr. 26, 2004; accepted Feb. 20, 2005; Published online Aug. 9, 2005
Predictors of serostatus disclosure were identified among youth living with HIV pre- and post-introduction of highly active antiretroviral therapy (HAART). Two cohorts of HIVpositive youth, aged 13-24, in 1994-1996 $(n=351)$ and 1999-2000 $(n=253)$ in Los Angeles, New York, San Francisco, and Miami were sampled through medical providers and a variety of social service agencies. Data were collected on demographic, social, medical, and behavioral topics. Men who had sex with men were more likely to disclose serostatus to their partners. Moreover, a positive association with length of time since diagnosis and the likelihood of disclosure exists; across time, youth were less likely to disclose serostatus to casual partners or HIV-negative partners. Post-HAART, number of sex acts with a partner was associated with increased likelihood of disclosure. Interventions for HIV-positive youth must improve disclosure to casual and serodiscordant sexual partners.
\end{abstract}

KEY WORDS: Serostatus; disclosure; HIV; adolescents; HAART.

\section{INTRODUCTION}

Of the estimated 5 million new HIV infections in 2003, The World Health Organization estimates that $50 \%$ of these infections were among young people between the age of 15 and 24 (UNAIDS, 2003), and $13 \%$ of reported US cases of HIV infection between 1996 and 1999 were among 13-24-year-olds (CDC, 2002). Relatively little work has been focused on issues of disclosure of HIV status by young seropositive people (D'Angelo et al., 2001; Lyon et al., 1999; Rotheram-Borus and Miller, 1998). Disclosure of HIV-positive status for any person living with HIV is a difficult and sometimes dangerous undertaking. Those who disclose risk rejection from partners, family and friends, and open themselves to the possibilities of discrimination and harassment because of

\footnotetext{
${ }^{1}$ Center for Community Health, University of California, Los Angeles, California.

${ }^{2}$ Correspondence should be directed to Mary Jane RotheramBorus, Center for Community Health, 10920 Wilshire Boulevard, Suite 350, Los Angeles, California 90024-6521; e-mail: rotheram@ucla.edu.
}

the stigma associated with positive status. Nonetheless, many individuals who are HIV-positive disclose their status to some or even all of their sex partners (D'Angelo et al., 2001; Greene and Serovich, 1996; Lyon et al., 1999; Mansergh et al., 1995; Marks et al., 1992; Marks and Crepaz, 2001; Schnell et al., 1992; Simoni et al., 1995; Sobel et al., 1996; Wolitski et al., 1998). Disclosure is crucial because it informs partners of potential risks, but recent research on a representative sample of adults living with HIV in the United States by Ciccarone and colleagues (2003) has shown $42 \%$ of gay or bisexual men, $19 \%$ of heterosexual men, and $17 \%$ of all women reported sex without disclosure since the discovery of their disease status.

Disclosure is not engaged in universally. Research on adolescent disclosure to sex partners has shown that primary partners are more likely to be disclosed to than casual partners (D'Angelo et al., 2001), and that young people living with HIV are more likely to disclose their serostatus to a partner whom they know to be HIV-positive (D'Angelo et al., 2001). Studies of disclosure patterns among 
adults support these findings and suggest other possible predictors. A large number of studies have established that primary partners are more likely to be informed as compared to one time or casual partners (Green, 1994; Niccolai et al., 1999; Norman et al., 1998; Wolitski et al., 1998). In addition, among adults there is an inverse relationship between the number of partners a person has and the likelihood of disclosure (Marks et al., 1991). Moreover, present and/or potential partners are more likely to be disclosed to versus past partners (Marks et al., 1992). There is a positive correlation between the length of time since diagnosis and the likelihood of disclosure to sex partners (Mansergh et al., 1995).

The introduction of highly active antiretroviral therapy (HAART) in the 1990s radically changed the face of the HIV/AIDS epidemic in the United States and other industrialized nations. Presumably, patterns of disclosure could also be a part of these broader changes. Obviously, those receiving HAART live longer and healthier lives, allowing these individuals to engage in more sexual activity. Likewise, recent reports have suggested that there has been a marked increase in high-risk sexual behaviors among men who have sex with men (MSM) who are living with HIV as well as among MSMs who are uninfected (Do et al., 2001; Dukers et al., 2001; Morin et al., 2003; Rietmeijer et al., 2003; Scheer et al., 2001; Stolte et al., 2001; Van de Ven et al., 2000), increasing concerns for the need for disclosure. The question as to how disclosure has been affected by the HAART era has yet to be explored, especially for young people, among whom these changes in sexual activity have been observed (Morin et al., 2003; Van de Ven et al., 2000). Given these worrisome new trends, this paper examines how predictors of disclosure of HIV status to sex partners among young people living with HIV may have changed since the advent of HAART.

\section{METHODS}

\section{Participants}

Two similar cohorts of youth living with HIV, each measured once 5 years apart, provided the data for the present study. The first cohort, labeled as pre-HAART, consisted of 351 youth aged 13-24, assessed between January 1994 and August 1996. Recruitment for this study was done at adolescent clinical care sites in four locations: Los Angeles,
New York, San Francisco, and Miami (for additional details on recruitment and study protocols see Rotheram-Borus et al., 2001). The second cohort, labeled as post-HAART, consisted of 253 youth living with HIV aged 13-29, assessed between May 1999 and December 2000 (for additional details on recruitment and study protocols see Comulada et al., 2003). To make the two projects comparable, the age of participants was restricted to include only those less than 24 years old. This restriction was due to the postHAART participants having a higher age limit than the pre-HAART participants.

Parental consent was obtained for youth under the age of 18 who were not emancipated minors and if the parent was aware of the youth's HIV status. Each participant was paid US\$20-25 to complete a baseline interview. Interviews for the project were performed in Los Angeles, New York, and San Francisco with youth recruited from medical providers, social service agencies, needle exchange programs, a drug treatment center, other research studies, and outreach through advertising and referrals.

Eligibility for both studies was established by provision of informed consent and the participant being sufficiently healthy at baseline to remain in the study. Participants in both studies were assessed using similar comprehensive computer-assisted interviews that covered a variety of demographic (e.g., age, race/ethnicity, gender), social (e.g., social support), medical (e.g., T-Cell count, physical health symptoms), and behavioral topics (recent and lifetime drug use, recent and lifetime sexual behaviors). Both interviews were primarily conducted by an interviewer with a computer-based interview, although the post-HAART study contained a selfadministered section using audio computer-assisted self-interview. Pre-HAART interviews typically lasted $3 \mathrm{~h}$, while post-HAART interviews were shorter, averaging approximately $2 \mathrm{~h}$.

\section{Procedures}

Interviewers were chosen to reflect the ethnic diversity of the participants and were trained to administer the assessment on site using laptop computers. Interviewer training covered research ethics, emergency procedures for suicidal/homicidal ideations, psychosocial and substance abuse assessments, sexual abuse reporting procedures, intensive review of assessment protocols, and mock interviews. 
An investigation of psychosocial intervention programs followed each of the baseline assessments, with follow-up assessments administered at regular intervals to monitor the progress. The present study used only the baseline data to compare the two cohorts on disclosure to sexual partners, as the interventions investigated by the two projects were different.

Assessments measured lifetime and current behaviors (operationalized as activities in the previous 3 months). Several strategies were employed to enhance overall recall, including: in depth probing of life events such as job or school changes, celebrations, relationships, places of residence, etc.; a timeline visual aid anchoring the 3,6, and 12 month time frames for these events; and frequent references during the entire interview to the timeline and the anchored events. Interviewers were trained to aid participants in summing behaviors over the different time frames and to confirm the accuracy of reporting using consistency checks and frequent probing.

\section{Data Set}

The data was structured hierarchically, with one record produced for each of the sex partners detailed by the participants, allowing for multiple records for each participant. The first level of the hierarchy consisted of participant-based variables, while the second level consisted of partner-based variables. Since specific information regarding sexual activity was provided for only the five most recent partners in the pre-HAART cohort, data for the sixth and subsequent partners were not considered. In both cohorts, disclosure was assessed in the same manner. Participants were asked about each of their most recent sex partners one at a time. With respect to each partner, participants were asked whether or not they had informed the partner that, "You were HIV-positive before you had vaginal or anal sex for the first time?"

\section{Analysis}

The generalized estimating equations (GEE) procedure was used to identify the covariates that were predictive of disclosure to partners. The hierarchical linear model was comprised of two levels: the participants at level 1 and the partners of each participant at level 2. An informal selection proce- dure, based on choosing the most highly predictive variables, was used to create a parsimonious model. Participants with missing data for variables in the final model were excluded from the analysis.

\section{RESULTS}

Table I displays the characteristics for the participants of the two studies. The two samples are quite similar on most dimensions. The characteristics that differed significantly between the two cohorts were the number of participants with a low CD4 count $\left(\chi^{2}(d f=1)=12.20, p<.001\right)$, the time since diagnosis $(t(d f=231)=4.29, p<.001)$, and the score on the Brief Symptom Inventory (BSI) $(t(d f=305)=1.99$, $p<.05)$. The decreased severity of illness in the preHAART group may be because that data was collected in the mid-1990s, when the AIDS epidemic was growing in the younger population, which was not enough time to have a large sample with the disease at a more progressed stage. The higher BSI scores observed in the post-HAART group were related to the increased severity of illness. A separate regression analysis demonstrated that the higher BSI scores seen in the post-HAART group were related to the increased severity of illness $(p<.05$ for $\log -\mathrm{CD} 4$ covariate in a multivariate regression controlling for project). Despite the availability of HAART to the post-HAART group, BSI was correlated with increased severity of illness for this cohort.

Table I. Demographics of Pre- and Post-HAART Cohorts

\begin{tabular}{lcc}
\hline & $\begin{array}{c}\text { Pre-HAART } \\
(n=345)\end{array}$ & $\begin{array}{c}\text { Post-HAART } \\
(n=166)\end{array}$ \\
\hline Male (\%) & 72.2 & 69.9 \\
Mean age $(S D)$ & $20.7(2.09)$ & $20.7(2.35)$ \\
Ethnic background & & \\
Caucasian (\%) & 18.6 & 16.3 \\
African-American (\%) & 27.3 & 31.9 \\
Latino (\%) & 36.5 & 32.5 \\
Other race/biracial $(\%)$ & 17.7 & 19.3 \\
Men who have sex with men & 63.5 & 65.2 \\
$\quad($ MSM) $(\%)$ & & \\
Health status & & \\
Mean log CD4 count $(S D)$ & $5.94(0.89)$ & $5.78(1.19)$ \\
CD4 $<200(\%)$ & 28.4 & $44.0^{* * *}$ \\
Mean years since diagnosis $(S D)$ & $2.19(1.11)$ & $3.46(3.46)^{* * *}$ \\
BSI aggregate score $(S D)$ & $48.2(39.5)$ & $56.0(41.1)^{*}$ \\
Mean no. of sex partners $(S D)$ & $5.66(26.4)$ & $5.34(15.9)$ \\
\hline${ }^{*} p<.05 ; * * *<.001$. & & \\
& &
\end{tabular}



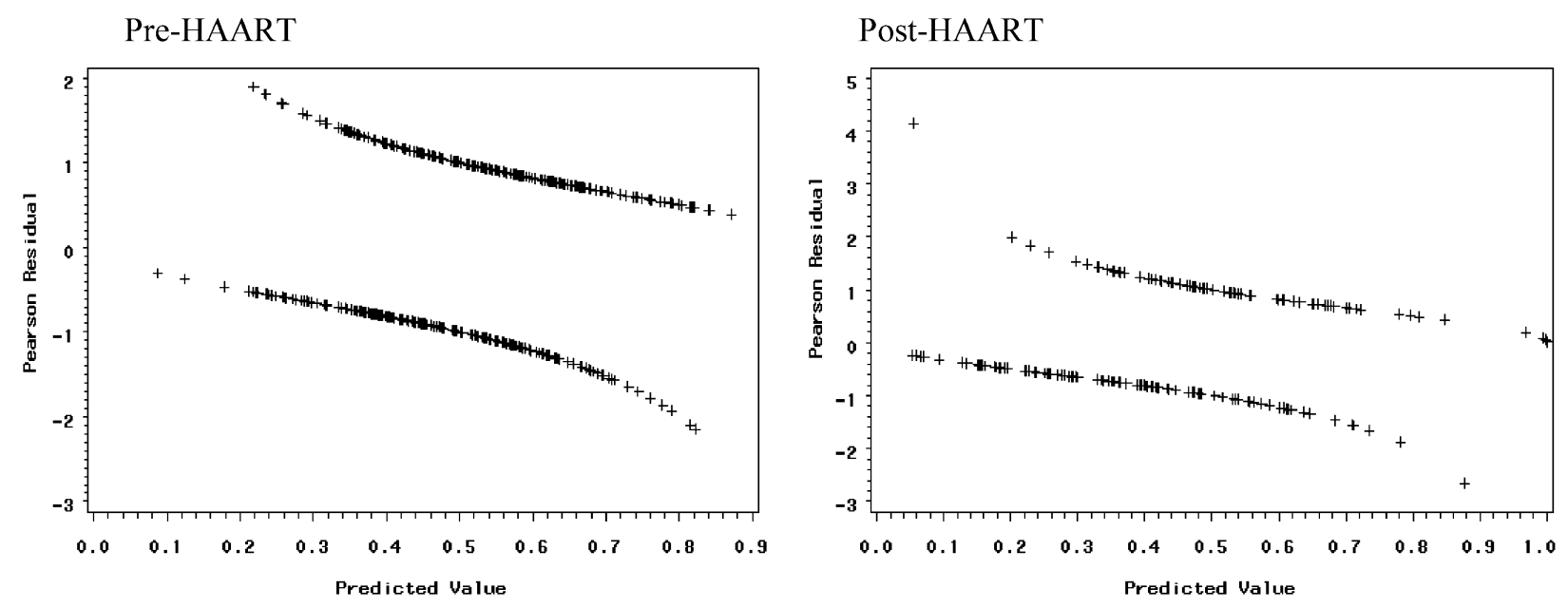

Fig. 1. Residual plots for the two samples.

\section{Predictors of Disclosure}

The GEE analysis examined several possible predictors of disclosure to sexual partners. This methodology was used because disclosure was treated as a binary outcome variable and the hierarchical nature of the data set precluded a simpler general linear model analysis. Since the two cohorts were shown to have disparate health characteristics, analyses were performed separately on each of the two data sets, although the same predictor variables were used in these analyses.

The first models that were tested included all the potential predictors that existed in the two data sets, along with two-way interaction terms for the predictors. All of the interaction terms and many of the main effects failed to reach significance. To create a more parsimonious model, the variables that failed to reach this significance for both of the data sets were eliminated from the models. The variables retained in the models were as follows: whether the participant was a MSM, participant's log time since HIV diagnosis, whether the partner was HIV-negative, whether the partner was casual, and the number of sex acts engaged in with a particular partner. The variables that were removed from the model were as follows: participant's age, participant's ethnic background, participant's BSI aggregate score, partner's gender, partner's age, and whether the participant had any unprotected sex with the partner. Current use and past use of antiretroviral drugs were included as predictors in the preliminary models for only the post-HAART data. These measures of antiretroviral drug use were not found to be significant predictors of disclosure within the post-HAART sample. The two final models were then tested for outliers using residual plots, shown in Fig. 1.

From the plots of predictive value versus Pearson residual, cutoff points were created that were based on where clear visual separation occurred between outlying observations. This criterion identified 8 observations from the pre-HAART data set and 11 observations from the post-HAART data set. The GEE analysis was re-run using the data sets with outliers removed to investigate how influential these points were on the outcome. The outliers were removed at the partner level, not the participant level, although eight participants had data from all of their partners removed. Since some of the main effects were altered by the exclusion of the outliers, the models without the outliers were adopted.

The final GEE analysis is displayed in Table II. The analysis used data for 547 partners over 243 participants in the pre-HAART project and 183 partners over 109 participants in the post-HAART project. Seventy pre-HAART and 45 post-HAART participants were abstinent in the 3 months prior to the interview and were consequently excluded from the analysis. A further 32 pre-HAART and 12 postHAART participants were excluded on the basis of missing data.

The results of the GEE analysis suggest that the odds of disclosure are increased for those young people who are MSM and who have had a longer time since diagnosis. The odds of disclosure to a particular partner are reduced if those partners were 
Table II. Generalized Estimating Equation (GEE) Parameter Estimates of Disclosure of HIV-Positive Status to Partners

\begin{tabular}{|c|c|c|c|c|c|c|c|c|c|c|}
\hline \multirow[b]{2}{*}{ Variable } & \multicolumn{5}{|c|}{ Pre-HAART } & \multicolumn{5}{|c|}{ Post-HAART } \\
\hline & Estimate & $S E$ & $p$-value & $\begin{array}{l}\text { Odds } \\
\text { ratio }\end{array}$ & $\begin{array}{c}\text { Confidence } \\
\text { interval }\end{array}$ & Estimate & $S E$ & $p$-value & $\begin{array}{l}\text { Odds } \\
\text { ratio }\end{array}$ & $\begin{array}{l}\text { Confidence } \\
\text { interval }\end{array}$ \\
\hline \multicolumn{11}{|c|}{ (A) Before removal of influential observations } \\
\hline & \multicolumn{5}{|c|}{$(n=243)$} & \multicolumn{5}{|c|}{$(n=109)$} \\
\hline Intercept & -1.123 & 0.721 & .119 & 0.325 & $(0.079,1.336)$ & -3.340 & 1.324 & .012 & 0.035 & $(0.003,0.474)$ \\
\hline $\operatorname{MSM}(\mathrm{Y} / \mathrm{N})$ & 0.507 & 0.259 & .051 & 1.661 & $(0.999,2.761)$ & 1.124 & 0.477 & .018 & 3.076 & $(1.208,7.828)$ \\
\hline $\begin{array}{l}\text { Log (time since } \\
\text { diagnosis) }\end{array}$ & 0.278 & 0.105 & .008 & 1.32 & $(1.076,1.621)$ & 0.395 & 0.177 & .025 & 1.485 & $(1.050,2.100)$ \\
\hline $\begin{array}{l}\text { Partner HIV negative } \\
(\mathrm{Y} / \mathrm{N})\end{array}$ & -0.683 & 0.209 & .001 & 0.505 & $(0.335,0.761)$ & -0.549 & 0.298 & .066 & 0.578 & $(0.322,1.036)$ \\
\hline Casual partner $(\mathrm{Y} / \mathrm{N})$ & -0.828 & 0.208 & $<.0001$ & 0.437 & $(0.291,0.657)$ & -0.577 & 0.325 & .076 & 0.562 & $(0.297,1.061)$ \\
\hline No. of sex acts & 0.002 & 0.004 & .600 & 1.002 & $(0.995,1.010)$ & 0.021 & 0.011 & .045 & 1.022 & $(1.001,1.043)$ \\
\hline \multicolumn{11}{|c|}{ (B) After removal of outliers } \\
\hline & \multicolumn{5}{|c|}{$(n=238)$} & \multicolumn{5}{|c|}{$(n=106)$} \\
\hline Intercept & -1.255 & 0.760 & .099 & 0.285 & $(0.064,1.265)$ & -4.093 & 1.376 & .003 & 0.017 & $(0.001,0.248)$ \\
\hline $\operatorname{MSM}(\mathrm{Y} / \mathrm{N})$ & 0.562 & 0.263 & .033 & 1.755 & $(1.048,2.938)$ & 1.385 & 0.493 & .005 & 3.994 & $(1.520,10.496)$ \\
\hline $\begin{array}{l}\text { Log (time since } \\
\text { diagnosis) }\end{array}$ & 0.296 & 0.110 & .007 & 1.345 & $(1.084,1.669)$ & 0.480 & 0.183 & .009 & 1.616 & $(1.129,2.313)$ \\
\hline $\begin{array}{l}\text { Partner HIV negative } \\
(\mathrm{Y} / \mathrm{N})\end{array}$ & -0.715 & 0.213 & .001 & 0.489 & $(0.322,0.743)$ & -0.556 & 0.303 & .067 & 0.574 & $(0.317,1.039)$ \\
\hline Casual partner $(\mathrm{Y} / \mathrm{N})$ & -0.849 & 0.211 & $<.0001$ & 0.428 & $(0.283,0.647)$ & -0.666 & 0.330 & .044 & 0.514 & $(0.269,0.981)$ \\
\hline No. of sex acts & 0.004 & 0.006 & .514 & 1.004 & $(0.992,1.016)$ & 0.027 & 0.012 & .024 & 1.027 & $(1.004,1.051)$ \\
\hline
\end{tabular}

considered casual or were known to be HIV negative (the $p$-value for this latter result is nearly .05, but fails to make the cutoff and is probably reflective of a lack of power).

Among the subset of MSM, there are two significant differences between those who disclosed their serostatus to their partners and those who did not. First, across both time periods, significantly more disclosers were white $(28 \%)$ as compared with their non-disclosing counterparts $(17 \%)$ $\left(\chi^{2}(d f=3)=9.09, p<.05\right)$. Second, disclosing MSM had known their HIV status, on average, approximately 1 year longer than non-disclosing MSM $(t(d f=300)=2.87, p<.01)$.

Moreover, among the subset of MSM, the characteristics of their partners differed on some important dimensions. Of those partners who did not receive disclosure, $57 \%$ were considered casual partners, whereas among those partners who did receive disclosure, only $43 \%$ were considered casual partners $\left(\chi^{2}=20.80 ; d f=1 ; p<.001\right)$. Likewise, of those partners who received disclosure, the mean number of sex acts with that partner was 12 compared to those partners who did not receive disclosure, who had an average of 6 sex acts $(t(d f=413)=2.88, p<.05)$. Finally, among those partners who received disclosure, only $43 \%$ were perceived to be HIV-negative by the respondent, whereas among those who were not disclosed to, $57 \%$ were believed to be HIV-negative $\left(\chi^{2}(d f=1)=21.13, p<.001\right)$. All of these trends are in the same direction as the trends for the sample as a whole described in the GEE model.

There is one difference that can be observed across the two time periods. The effect of the number of sex acts with the partner was significant only in the post-HAART project, a result that is unlikely to be related to issues of power, but rather reflective of changes in the importance of sexual activity to disclosure in the post-HAART era.

\section{DISCUSSION}

There are several important findings that emerged from this study. First, there has been a great deal of consistency in factors that predict disclosure among young people across the pre- and postHAART eras, factors that have been observed in earlier samples of HIV-positive people. For young people there is a positive relationship between the length of time since serostatus diagnosis and disclosure to sex partners, a finding that has been 
observed previously among some samples of adults (e.g., Marks et al., 1992). Young people were less likely to disclose serostatus to HIV-negative partners and were also less likely to disclose serostatus to casual partners at both time points.

Second, the one important difference in the predictors of disclosure in the pre- and post-HAART eras is the effect of number of sex acts on the likelihood of disclosure. In the post-HAART era, a positive relationship between the number of sex acts a young person engages in and the likelihood of disclosure has emerged, an association absent in the earlier period. Youth who are having more sex with particular partners are more likely to disclose their serostatus to those partners, which may partly reflect a greater level of involvement with that partner.

Third, in stark contrast to recent reports of disclosure among adults, in both time periods observed here, young MSMs were more likely to disclose to their partners. Recent research has shown that in a representative sample of adults living with HIV, MSMs are the group most likely to have sex without disclosure (Ciccarone et al., 2003). The results presented here, however, show that among young people, MSMs in both the pre- and post-HAART periods were more likely to disclose serostatus to their partners, relative to heterosexual youth. Perhaps this finding reflects the relative openness of communication about HIV and HIV-related issues among MSM as compared to heterosexual youth. Discourse surrounding HIV is arguably more public among MSM than any other group in the United States. While stigma surrounding HIV still exists, HIV awareness is high, and the relative disclosure rates may be in part a reflection of this relative openness in the discussion of HIV among MSM as compared to heterosexual youth.

Fourth, there are a few important characteristics of MSM who disclosed versus those who did not. More MSM who disclosed were White, relative to non-disclosers, and disclosing MSM had known of their HIV status for longer than non-disclosing MSM. This suggests that learning the skills to successfully disclose one's serostatus to sexual partners may take time to develop. It also suggests White MSM, who have been the most intense focus of HIV-prevention efforts in the United States, may have been provided with more assistance than other groups in learning and developing these skills. Moreover, HIV-related stigma may be greater among nonWhite MSM as compared to White MSM, making disclosure even more difficult for those men.
There are some limitations to the present analysis. We are unable to compare changes in the effect size of predictors of serostatus disclosure to partners across the two time periods. Because the analysis presented here draws on data from two different intervention studies and the questions asked in each study differed slightly, we were unable to combine our samples into one analysis. Thus, we are limited to comparing what factors were predictive at each time period but we cannot assess how the strength of these associations may have changed from the pre- to postHAART period.

Future interventions must be focused on prevention for persons living with HIV. As HAART has radically changed the face of the AIDS epidemic in the United States, youth living with HIV continue to be less likely to disclose their serostatus to casual partners and partners whom they know to be HIV negative. While there is no guarantee that disclosure will result in safer sex or that a failure to disclose will result in unprotected sex (Crepaz and Marks, 2002), disclosure of serostatus is important so that partners can make informed decisions about their sexual activities. It is crucial that new intervention efforts be directed at these sexually active young people who are failing to provide information about their serostatus to their partners.

\section{ACKNOWLEDGMENTS}

The research for this article was completed with the support of grant R01 DA-07903 from the National Institute on Drug Abuse.

\section{REFERENCES}

Centers for Disease Control and Prevention (CDC). (2002). Young people at risk: HIV/AIDS among America's Youth. Retrieved February 4, 2004, from http://www.cdc.gov/hiv/ pubs/facts/youth.htm

Ciccarone, D. H., Kanouse, D. E., Collins, R. L., Miu, A. Chen, J. L., Morton, S. C., and Stall, R. (2003). Sex without disclosure of positive HIV serostatus in a US probability sample of persons receiving medical care for HIV infection. American Journal of Public Health, 93, 949-954.

Comulada, W. S., Swendeman, D. T., Rotheram-Borus, M. J., Mattes, K. M., and Weiss, R. E. (2003). Use of HAART among young people living with HIV. American Journal of Health Behavior, 27(4), 389-400.

Crepaz, N., and Marks, G. (2002). Towards and understanding of sexual risk behavior in people living with HIV: A review of social, psychological, and medical findings. AIDS, 16, 135-149.

D’Angelo, L. J., Abdalian, S. E., Sarr, M., Hoffman, N., Belzer, M., and the Adolescent Medicine HIV/AIDS 
Research Network. (2001). Disclosure of serostatus by HIV infected youth: The experience of the REACH study. Journal of Adolescent Health, 29S, 72-79.

Do, A. N., Hanson, D. L., Dworkin, M. S., and Jones, J. L. (2001). Risk factors for and trends in gonorrhea incidence among persons infected with HIV in the United States. AIDS, 15, 11491155.

Dukers, N. H., Goudsmit, J., de Wit, J. B., Prins, M., Weverling, G. J., and Coutinhol, R. A. (2001). Sexual risk behavior relates to the virological and immunological improvement during high active antiretroviral therapy in HIV-1 infection. AIDS, 15, 369-378.

Green, G. (1994). Positive sex: Sexual relationships following an HIV-positive diagnosis. In P. Aggleton, P. Davies, and G. Hart (Eds.), AIDS: Foundations for the future (pp. 136-146). London: Taylor and Francis.

Greene, K., and Serovich, J. M. (1996). Appropriateness of disclosure of HIV testing information: The perspective from PLWAs. Journal of Applied Communication Research, 24, $50-65$.

Lyon, M., Brasseux, C., and D'Angelo, L. J. (1999). Who should I tell? Disclosure of HIV status by infected adolescents (Abstract). Journal of Adolescent Health, 24, 120.

Mansergh, G., Marks, G., and Simon, J. M. (1995). Self-disclosure of HIV infection among men who vary in time since seropositive diagnosis and symptomatic status. AIDS, 9, 639644.

Marks, G., and Crepaz, N. (2001). HIV-positive men's sexual practices in the context of self-disclosure of HIV status. Journal of Acquired Immune Deficiency Syndrome, 27, 79-85.

Marks, G., Richardson, J. L., and Maldonado, N. (1991). Selfdisclosure of HIV infection to sexual partners. American Journal of Public Health, 81, 1321-1323.

Marks, G., Bundek, N. I., Richardson, J. L., Ruiz, M. S., Maldonado, N., and Mason, H. R. (1992). Self-disclosure of HIV infection: Preliminary results from a sample of Hispanic men. Health Psychology, 11, 300-306.

Morin, S. F., Vernon, K., Jarcourt, J., Steward, W. T., Volk, J., Riess, T. H., Neilands, T. B., McLaughlin, M., and Coates, T. J. (2003). Why HIV infections have increased among men who have sex with men and what to do about it: Findings from California focus groups. AIDS and Behavior, 7, 353362.

Niccolai, L. M., Dorst, D., Myers, L., and Kissinger, P. J. (1999). Disclosure of HIV status to sexual partners: predictors and temporal patterns. Sexually Transmitted Diseases, 26, 281285.
Norman, L. R., Kennedy, M., and Parish, K. (1998). Closer relationships and safer sex among HIV-infected men with haemophilia. AIDS Care, 10, 339-354.

Rietmeijer, C. A., Patnaik, J. L., Judson, F. N., and Douglas, J. M. (2003). Increases in gonorrhea and sexual risk behaviors among men who have sex with me: A 12-year trend analysis at the Denver Metro Health Clinic. Sexually Transmitted Diseases, 30, 562-567.

Rotheram-Borus, M. J., and Miller, S. (1998). Secondary prevention for youth living with HIV. AIDS Care, 10, 17-34.

Rotheram-Borus, M. J., Lee, M. B., Murphy, D. A., Futterman, D., Duan, N., Birnbaum, J., and the Teens Linked To Care Consortium. (2001). Efficacy of a preventive intervention for youth living with HIV. American Journal of Public Health, 91, 400-405.

Scheer, S., Chu, P. L., Klausner, J. D., Katz, M. H., and Schwarcz, S. K. (2001). Effect of highly active antiretroviral therapy on diagnoses of sexually transmitted diseases in people with AIDS. Lancet, 357, 432-435.

Schnell, D. J., Higgins, D. L., Wilson, R. M., Goldbaum, G., Cohn, D. L., and Wolitski, R. J. (1992). Men's disclosure of HIV test results to male primary sex partners. American Journal of Public Health, 82, 1675-1676.

Simoni, J. M., Masons, H. R., Marks, G., Ruiz, M. S., Reed, D., and Richardson, J. L. (1995). Women's self-disclosure of HIV infection: Rates, reasons, reactions. Journal of Consulting and Clinical Psychology, 63, 474-478.

Sobel, E., Shine, D., DiPietro, D., and Rabinowitz, M. (1996). Condom use among HIV-infected patients in South Bronx, New York. AIDS, 10, 235-236.

Stolte, I. G., Dukers, N. H., de Wit, J. B., Fennema, J. S., and Coutihno, R. A. (2001). Increase in sexually transmitted infection among homosexual men in Amsterdam in relation to HAART. Sexually Transmitted Infections, 77(3), 184-186.

UNAIDS. AIDS Epidemic Update 2003. Retrieved August 18, 2004, from http://www.unaids.org/Unaids/EN/Resources/ Publications/corporate+publications/aids+epidemic + update +-+ december+2003.asp

Van de Ven, P., Prestage, G., Crawford, J., Grulich, A., and Kippax, S. (2000). Sexual risk behaviour increases and is associated with HIV optimism among HIV-negative and HIVpositive gay men in Sydney over the 4 year period to February 2000. AIDS, 14, 2951-2953.

Wolitski, R. J., Rietmeijer, C. A. M., Goldbaum, G. M., and Wilson, R. M. (1998). HIV serostatus disclosure among gay and bisexual men in four American cities: General patterns and relation to sexual practices. AIDS Care, 10, 599-610. 